\title{
Knowledge of Student Nurses Regarding Interpretation of Electrocardiogram: A Pre-Experimental Study
}

\author{
Neha $K^{*}$, Bist M, Dixit K and Pareek S \\ Miranda college of Nursing, India
}

*Corresponding author: Kumari Neha, Miranda college of Nursing, Bangalore, VPOJhalta, Tehsil- Jabbal. District- Shimla, Himachal Pradesh Pin- 171216, India, Tel: 09999449065; Email: shatrughan.pareek@gmail.com

\section{Research Article \\ Volume 3 Issue 6}

Received Date: November 16, 2019

Published Date: December 03, 2019

DOI: $10.23880 /$ nhij-16000209

\section{Abstract}

Introduction: Cardiovascular disease is the leading cause of death in many regions worldwide, accounting for nearly one third of global deaths. Electrocardiography is the most commonly used diagnostic procedure in cardiology. If ECG properly interpreted, it contributes significantly to the diagnosis and management of patients with cardiac disorders.

Methodology: In the present study, one group Pre-test post-test design was selected to assess the effectiveness of computer simulated teaching on E.C.G and its interpretation among nursing students. The study was conducted among 60 B. Sc. Nursing ( $3^{\text {rd }} \& 4^{\text {th }}$ Year) Students at Miranda College of Nursing, Bangalore. The samples were selected by nonprobability purposive sampling technique.

Results: In the present study, $50 \%$ of the respondents fall between the ages of 19-22 years. Majority of the respondents (87\%) were females. Majority of the respondents 73\% were Hindus, 23\% Christians and remaining 4\% were Muslims. The pretest mean knowledge score was 17.33 and post test score was 30.88 with paired " $t$ " test value of 31.894 which was significant at 0.05 levels. There was significant association among level of knowledge and religion, father's education and source of information.

Discussion: The knowledge regarding ECG interpretation is crucial for the student nurses. Early diagnosis may save the life of cardiac patient. ECG interpretation knowledge can be pivotal in clinical practice and academic. There should be an orientation program for nurses to enhance the knowledge regarding ECG interpretation.

Keywords: ECG; Interpretation; Knowledge; Student Nurses; Students

Abbreviations: CVDs: Cardiovascular diseases; ECG: Electrocardiogram; SCA: Sudden Cardiac Arrest; ECG: Electro Cardiogram; STP: Structured Teaching Program.

\section{Introduction}

The occurrence of Coronary artery disease is 2 to 4 times higher among persons who have Diabetes. Around 


\section{Nursing \& Healthcare International Journal}

$25 \%$ of total deaths occur due to Coronary vascular diseases. As per WHO, Coronary artery disease death rates are 3 times higher than Coronary vascular diseases. The burden of cardiac diseases is around the world is increasing with great pace. The mortality due to cardiac disorders is projected to increase to 23.4 million in 2030 [1]. Cardiovascular diseases (CVDs) have now become the leading cause of mortality in India. The Global Burden of Disease study estimated that CVD death rate in India is 272 per $1,00,000$ population which is higher than the global average of 235 per 1,00,000 population [2]. The current status of heart diseases in India is alarming. About 29 seconds, an Indian dies with heart problems. As many as 20,000 new heart patients develop every day in India. By 2020, India will have the largest coronary heart disease burden in the world and will account for one third of all deaths; it is estimated that 17.5 million people die each year in India from cardiovascular diseases, amounting to a staggering $31 \%$ of all deaths worldwide [3]. Electrocardiogram (ECG) is a non-invasive procedure which commonly formed in medicine and emergency departments. ECG interpretation skill is desirable for the nurses to assess and manage the cardiac emergency [4]. The first practical ECG was introduced by William Einthoven is in 1901. In 1924 Einthoven received the Nobel Prize for his life's work in developing the ECG. By 1937, portable ECG was invented by Taro Takemi [5]. An electrocardiogram measures the electrical activity of the heart and can be used to diagnose a range of heart diseases. The process of taking an ECG involves attaching a series of electrodes to the patient's chest and limbs, and printing a recording on the ECG machine for interpretation. It is also used to monitor recovery from a myocardial infraction [6]. Electrocardiography is the most commonly used diagnostic tool in cardiology. If properly interpreted, it contributes significantly to the diagnosis and management of patients with cardiac disorders. Importantly, it is essential to the diagnosis of cardiac arrhythmias and the acute myocardial ischemic syndromes. These two conditions account for the majority of cardiac catastrophes. It is appropriately used as a screening test in many circumstances [7]. Basic knowledge of the ECG is usually the most difficult to assimilate, as it implies learning the basis of interpretation. With technological advances, changes in provision of healthcare services and increasing pressure on critical care services, ward patients' severity of illness is ever increasing [8]. A recent report in 2010 shows that $60 \%$ of the world's heart patients are in India. Approximately $60 \%$ of all cardiac deaths occur due to arrhythmias leading to Sudden Cardiac Arrest (SCA) in India [9]. As such, nurses need to develop their skills and knowledge to care for their client group. Competency in cardiac rhythm monitoring is beneficial to identify changes in cardiac status, assess response to treatment, diagnosis and postsurgical monitoring [9]. Every nursing student, nurse or even resident doctor must be aware of the importance of correlating clinical findings after a complete examination with the ECG finding. A good basic ECG interpretation may rely on the ability to combine clinical skills with basic ECG interpretation. ECG is an important tool used for the diagnosis and treatment of various cardiac and other related diseases. The recorded traces of ECG waveform produced by heart can tell you basic information about patient's condition. The ability to evaluate various ECG waveforms is an important skill for many health care professionals including nurses, doctors and medical assistants [10]. If nurses are able to interpret electro cardiogram (ECG) not only their knowledge base increases but the detection and treatment of chronic or acute cardiac problems will also improve. Considering the severity of the life threatening condition this was selected to impart knowledge to the nursing students to become competent to obtain and interpret ECG. From the personal experiences while working as a staff nurse in cardiology department, the researcher felt a need to conduct a study to determine the effectiveness of computer assisted teaching on ECG interpretation of selected cardiac conditions for nursing students with the main objective of improving their knowledge.

\section{Methodology}

The present study aimed at determining the effectiveness of a computer assisted teaching on ECG and its interpretation among B.Sc. Nursing students, by using an evaluative approach. One group Pre-test post-test design was selected to assess the effectiveness of computer simulated teaching on ECG and its interpretation among nursing students. In this study, the Computer assisted teaching on ECG was the independent variable and knowledge level of nursing students regarding ECG and its interpretation was considered as dependent variable. The study was conducted at Miranda College of Nursing, Bangalore among 60 B. Sc. Nursing $3^{\text {rd }}$ $\& 4^{\text {th }}$ Year) Students. The samples were selected by nonprobability purposive sampling technique. Formal Permission was obtained from concerned authorities to conduct the study. Purpose of the study was explained to the subjects and consent was taken. Pretest was conducted with the structured questionnaire. Computed assisted teaching module was administered to the samples and post test was conducted after 7 days. The maximum knowledge score regarding interpretation of 
ECG was 40. Knowledge scores were classified on the basis of obtained score in 3 categories. Score less than $50 \%$ considered as inadequate, scores between 50-72.5\% and above $75 \%$ were considered moderate and adequate respectively.

\section{Results}

\begin{tabular}{|c|c|c|c|c|}
\hline \multirow{2}{*}{ Characteristics } & \multicolumn{4}{|c|}{ Respondents } \\
\hline & Category & frequency & Percentage & Total \\
\hline \multirow{3}{*}{ Age (years) } & Below 19 & 24 & $40 \%$ & \multirow{3}{*}{60} \\
\hline & $19-22$ & 30 & $50 \%$ & \\
\hline & Above 22 & 6 & $10 \%$ & \\
\hline \multirow{2}{*}{ Gender } & Male & 8 & $13 \%$ & \multirow{2}{*}{60} \\
\hline & Female & 52 & $87 \%$ & \\
\hline \multirow{4}{*}{ Religion } & Hindu & 44 & $73 \%$ & \multirow{4}{*}{60} \\
\hline & Christian & 14 & $23 \%$ & \\
\hline & Muslim & 2 & $4 \%$ & \\
\hline & Others & 0 & $0 \%$ & \\
\hline \multirow{4}{*}{ Source of information } & Demonstration & 30 & $50 \%$ & \multirow{4}{*}{60} \\
\hline & Classroom teaching & 25 & $42 \%$ & \\
\hline & Clinical experience & 5 & $8 \%$ & \\
\hline & Others & 0 & $0 \%$ & \\
\hline
\end{tabular}

Table 1: Classification of Demographic Profile N=60.

\begin{tabular}{|c|c|c|c|c|c|}
\hline \multirow{2}{*}{ Knowledge Level } & \multirow{2}{*}{ Category } & \multicolumn{2}{|c|}{ Pretest } & \multicolumn{2}{c|}{ Post-test } \\
\cline { 3 - 6 } & $\leq 20(\leq 50 \%)$ & $\mathbf{N}$ & $\mathbf{\%}$ & $\mathbf{N}$ & $\mathbf{\%}$ \\
\hline Inadequate & $20-29(50-72.5 \%)$ & 11 & 18 & 15 & 25 \\
\hline Moderate & $\begin{array}{c}30 \& \text { above } \\
(75 \% \text { \& above })\end{array}$ & 0 & 0 & 45 & 75 \\
\hline Adequate & Total & $\mathbf{6 0}$ & $\mathbf{1 0 0}$ & $\mathbf{6 0}$ & $\mathbf{1 0 0}$ \\
\hline
\end{tabular}

Table 2: Pretest \& posttest knowledge level on interpretation of ECG N=60.

\begin{tabular}{|c|c|c|c|c|c|}
\hline \multirow{2}{*}{ Evaluation } & \multirow{2}{*}{ Max. Score } & \multicolumn{3}{|c|}{ Respondents Knowledge } & \multirow{2}{*}{ Paired 't' Test } \\
\cline { 3 - 5 } & & Mean & SD & Mean (\%) & \multirow{2}{*}{$31.894^{*}$} \\
\hline Pre test & 40 & 17.33 & 2.5 & 43.33 & 77.21 \\
\hline Post test & 40 & 30.88 & 2.1 & \\
\hline
\end{tabular}

Table 3: Pretest \& posttest knowledge score and " $t$ " value on interpretation of ECG $N=60$.

*Significant at 0.05 level, $\mathrm{t}$-value $(0.05,59 \mathrm{df})=1.96$

\begin{tabular}{|c|c|c|c|c|c|c|c|c|}
\hline \multirow{3}{*}{ Demographic Variables } & \multirow{3}{*}{ Category } & \multirow{3}{*}{ Sample } & \multicolumn{4}{|c|}{ Respondents Knowledge } & \multirow{3}{*}{ Chi-square Value } & \multirow{3}{*}{ P Value } \\
\hline & & & \multicolumn{2}{|c|}{ Moderate } & \multicolumn{2}{|c|}{ Adequate } & & \\
\hline & & & $\mathbf{N}$ & $\%$ & $\mathbf{N}$ & $\%$ & & \\
\hline \multirow{3}{*}{ Age (years) } & Above 22 years & 24 & 6 & 25 & 18 & 75 & \multirow{3}{*}{$0.267 \mathrm{NS}$} & \multirow{3}{*}{0.8752} \\
\hline & $19-22$ & 30 & 7 & 23 & 23 & 77 & & \\
\hline & Below 19 & 6 & 2 & 33 & 4 & 67 & & \\
\hline \multirow{3}{*}{ Gender } & Male & 8 & 3 & 37.5 & 5 & 62.5 & \multirow{2}{*}{$0.382 \mathrm{NS}$} & \multirow{2}{*}{0.536} \\
\hline & Female & 52 & 14 & 26.9 & 38 & 73.1 & & \\
\hline & Hindu & 44 & 9 & 20.45 & 35 & 79.55 & & \\
\hline
\end{tabular}




\section{Nursing \& Healthcare International Journal}

\begin{tabular}{|c|c|c|c|c|c|c|c|c|}
\hline \multirow{3}{*}{ Religion } & Christian & 14 & 3 & 21.42 & 11 & 78.58 & \multirow{3}{*}{$0.985^{*}$} & \multirow{3}{*}{0.6112} \\
\hline & Muslim & 2 & 1 & 50 & 1 & 50 & & \\
\hline & Others & 0 & 0 & 0 & 0 & 0 & & \\
\hline \multirow{4}{*}{ Father's Educational Status } & Post Graduate \& Above & 21 & 8 & 38.09 & 13 & 61.91 & \multirow{4}{*}{$3.247^{*}$} & \multirow{4}{*}{0.197} \\
\hline & Graduation & 30 & 6 & 20 & 24 & 80 & & \\
\hline & $\begin{array}{c}\text { Primary Education \& } \\
\text { Above }\end{array}$ & 9 & 1 & 11.1 & 8 & 88.8 & & \\
\hline & No formal Education & 0 & 0 & - & 0 & - & & \\
\hline \multirow{4}{*}{ Source of Information } & Demonstration & 30 & 6 & 20 & 24 & 80 & \multirow{4}{*}{$3.545^{*}$} & \multirow{4}{*}{0.1699} \\
\hline & Class room teaching & 25 & 7 & 28 & 18 & 72 & & \\
\hline & Clinical experience & 5 & 3 & 60 & 2 & 40 & & \\
\hline & Others & 0 & 0 & - & 0 & - & & \\
\hline
\end{tabular}

Table 4: Association between age in years and posttest knowledge level on interpretation of ECG N=60. NS: Non-significant $\chi^{2}(0.05,2 \mathrm{df})=5.99$

\section{Discussion}

ECG monitoring and interpretation skills are gained in medical education and strengthened by experience. However, the need for immediate pattern recognition and subsequent procedures involves nurses in the process of evaluation, registration and initiation of reperfusion therapies as well as in the detection of complications and the request for assistance. The mean pretest knowledge score was 17.33 and posttest knowledge score was 30.88 . The calculated " $\mathrm{t}$ " value was 31.894 which are significant at 0.05 levels. It indicated that computer assisted teaching program was effective to enhance the knowledge of nursing students regarding interpretation of Electrocardiogram. The findings are supported by simulation based study conducted by Smith MW, et al. (2019) on predicting electrocardiogram interpretation performance in Advanced Cardiovascular Life Support simulation among medical students. The study revealed that simulation technique was effective to enhance the knowledge of the students [11,12]. Ranjana (2018) conducted a study among 60 B.Sc nursing students on knowledge of ECG interpretation. The researcher implemented a structured teaching program (STP) to assess its effectiveness. The pretest knowledge score was $26.4 \%$ and after implementation of STP the students' knowledge up to $71 \%$ regarding ECG. The study revealed that STP was effective to increase the knowledge of nursing students regarding interpretation of ECG. The present study's findings were supported by study conducted by Ranjana (2018) [13]. The present study communicated that there were significant association of knowledge scores with selected socio demographic variables i.e. Religion, father's educational status and source of information. There were no studies to support the present findings. Nurses who are trained to read ECG can improve patient care through the early identification of actual or potential complications and the prompt referral.

\section{Conclusion}

ECG interpretation is very crucial for health care professionals. ECG is a non-invasive procedure which commonly formed in medicine and emergency departments. The results of present study showed the effectiveness of Computed assisted teaching module on ECG interpretation among student nurses. There is a clear need to use various teaching activities and educational program to enhance the knowledge and practices of ECG interpretation. Early diagnosis of cardiac disorders can help the doctors and nurses to save patient's life. It will be effective in reducing morbidity and mortality due to cardiac diseases. The administrators have to emphasis on organizing and implementing different educational activities and modules regarding ECG interpretation. These initiatives will be effective tool to enhance the knowledge of nursing professionals.

\section{Conflicts of Interest}

The authors have no conflicts of interest with respect to the publication of this paper.

\section{References}

1. Pareek S, Kaushik NK (2018) Implementation and Outcomes of Cardiac Rehabilitation Educational Package: A Tertiary Center Study. Int J Nur Edu Res 6(4): 401-403. 
2. Leanne A, Brannigan D (2003) Cardiac Monitors friends or foe. Nur Times 4(5): 25-26.

3. Funket M (2010) Deficiencies in nurses'knowledge and substandard practice related to ECG monitoring. European J Cardio Nur 12(9): 12-15.

4. Werner K, Kander K, Axelsson C (2016) Electrocardiogram interpretation skills among ambulance nurses. Eur J Cardiovasc Nurs 15(4): 262268.

5. Eduesley SS, Emile CP, Juliana TS, Vanessa SS, Diego G, et al. (2017) Ability of Nurses interpret a 12-lead Electrocardiography. Baiana J Nur 31(1): 1-8.

6. Kimberly S, Chelsea H, Elisabeth H (2006) Deficiencies in nurses' knowledge and substandard practice related to ECG monitoring: multisite randomized clinical trial. Cardio thoracic J 7(4): 3643.

7. McGrath A, Sampson M (2018) Electrocardiograms: a guide to rhythm recognition for emergency nurses. Emergency Nurse 26(1): 21-29.

8. Chadha SL, Gopianth N, Ramachadran K (1992) Epidemiological study of coronary heart disease in
Guajarati's in Delhi (India). Indian J Med Res 96: 115121.

9. (2002) Together for health, Publication assessment global health, Switzerland.

10. (2000) Indian health survey, an expert assessment of health in India. Assessment report, India.

11. (2007) Cardiovascular Technologists and Technicians, US Department of Labor, Bureau of Labor Statistics, pp: 8-31.

12. Smith MW, Abarca Rondero D (2019) Predicting electrocardiogram interpretation performance in Advanced Cardiovascular Life Support simulation: comparing knowledge tests and simulation performance among Mexican medical students. Peer J 7: e6632.

13. Ranjana (2018) A study to evaluate the effectiveness of structured teaching programme on knowledge regarding interpretation of Electrocardiogram (ECG) among second Year Bsc Nursing Students in selected college of Nursing at Raipur. Int Edu Res J 4(9): 19-21. 